\title{
The Emerging Role of Interleukin-21 in Transplantation
}

\author{
Aini Xie ${ }^{1,2}$, Eric Dale Buras ${ }^{1}$, Jiahong $\mathrm{Xia}^{2,{ }^{*} \text {, and Wenhao Chen }}{ }^{1,{ }^{*}}$ \\ ${ }^{1}$ Division of Diabetes, Endocrinology and Metabolism, Department of Medicine, Baylor College of \\ Medicine, Houston, TX, 77030, USA \\ 2Department of Cardiovascular Surgery, Union Hospital, Huazhong University of Science and \\ Technology, Wuhan, Hubei, 430022, China
}

\begin{abstract}
Since its discovery in 2000, IL-21 has been shown to play critical roles in the regulation of both innate and adaptive immune responses. IL-21 is produced predominantly by multiple effector $\mathrm{CD}^{+} \mathrm{T}$-cell types [T helper 17 (Th17), follicular helper $\mathrm{T}\left(\mathrm{T}_{\mathrm{FH}}\right)$, and other activated $\mathrm{CD} 4^{+}$cells] and NKT cells. In addition to T cell receptor (TCR) signals, the production of IL-21 by activated $\mathrm{CD}^{+} \mathrm{T}$ cells is intricately regulated by various extrinsic factors and intrinsic molecules, such as IL-6, IL-21, ICOS, Stat3, IRF4, and Batf. Because IL-21 receptor (IL-21R) is broadly expressed on T, B, NK, and dentritic cells (DCs), IL-21 signaling via Jak-Stat and other pathways has direct pleiotropic effects on their proliferation, differentiation, and effector function. For instance, while Th17 and $\mathrm{T}_{\mathrm{FH}}$ cells produce IL-21, IL-21 also facilitates the development of these cells. IL-21producing $\mathrm{T}_{\mathrm{FH}}$ cells are important for the generation and maintenance of germinal centers, and control the differentiation of germinal center B cells and immunoglobulin production. Thus, IL-21R deficiency or IL-21 neutralization with IL-21R-Fc fusion protein prevents B cell-mediated autoimmunity in lupus-prone BXSB.B6- $\mathrm{Ya}^{+}$or MRL-Fas ${ }^{\mathrm{lpr}}$ mouse models, respectively. IL-21 also enhances expansion and cytotoxicity of $\mathrm{CD} 8^{+}$effector $\mathrm{T}$ cells. During chronic lymphocytic choriomeningitis viral infection, chronic IL-21 production by antigen-specific $\mathrm{CD} 4^{+} \mathrm{T}$ cells is needed to sustain $\mathrm{CD} 8^{+} \mathrm{T}$ cell function for viral control. IL-21 is also required for the development of T cell-mediated type 1 diabetes in NOD mice, possibly through sustaining effector $\mathrm{T}$ cell function in a similar manner. Recently, two papers have shown that IL-21R-Fc prevents both auto- and allo-immune responses after islet transplantation. A timely discussion is thus needed to address the immune actions of IL-21 as well as the therapeutic potential of targeting IL-21 in transplantation.
\end{abstract}

\section{Keywords}

IL-21; T cells; B cells; Transplantation; Tolerance

\footnotetext{
Copyright: () 2012 Xie A, et al.

*Corresponding authors: Wenhao Chen, Division of Diabetes, Endocrinology and Metabolism, Department of Medicine, Baylor College of Medicine, One Baylor Plaza (MS: BCM185), Houston, TX, 77030, USA, Tel: 713-798-1698; Fax: 713-798-4575; wenhaoc@bcm.edu. Jiahong Xia, Department of Cardiovascular Surgery, Union Hospital, Huazhong University of Science and Technology, Wuhan Jiefang Road 1277\#, Wuhan, Hubei, 430022, China, Tel: 0086-13971038472; Fax: 0086-27-85355457; jiahong.xia@mail.hust.edu.cn.

This is an open-access article distributed under the terms of the Creative Commons Attribution License, which permits unrestricted use, distribution, and reproduction in any medium, provided the original author and source are credited.
} 


\section{Introduction}

The survival of human transplants depends on continual use of immunosuppressive drugs that non-selectively impair immune cell function. While long-term (> 5-year) graft survival with chronic immunosuppression remains poor, these therapies are also complicated by numerous side effects. Therefore, a major challenge of the transplantation field is to develop methods to induce immune tolerance to transplanted organs, a state in which lymphocytes reactive to allogeneic antigens are selectively eliminated or inactivated while other components of the immune system remain intact [1].

IL-21 is mainly produced by activated $\mathrm{CD}^{+} \mathrm{T}$ cells and controls plasma cell differentiation and antibody production, as well as NK cell activity [2]. Most importantly, the chronic production of IL-21 by activated CD $4^{+} \mathrm{T}$ cells is needed to sustain effector $\mathrm{T}$ cell function for viral control and autoimmune destruction [3-7]. In other words, chronic IL-21deprivation in the extrinsic environment may lead to "exhaustive differentiation" of effector T cells, defined as poor effector function [8]. Thus, blocking IL-21 production and signaling in alloreactive $\mathrm{T}$ cells may provide a unique therapeutic strategy for targeting the late-phase alloimmune response [9]. This strategy is fundamentally different from most immune therapies, which aim to prevent the occurrence of alloimmune responses. Two independent groups have recently reported that neutralizing IL-21 by IL-21R-Fc treatment induces longterm islet graft survival [7,9]. Therefore, in this review, we discuss the immune regulative activity of IL-21 as well as the therapeutic potential of blocking IL-21 signaling in the induction of transplantation tolerance.

\section{IL-21 is the Most Recently Identified Common y-chain Family Cytokine}

In the year 2000, Parrish-Novak et al. [10] and Ozaki et al. [11] identified a class I cytokine receptor selectively expressed in lymphoid tissues. Parrish-Novak et al. [10] generated a cell line expressing this receptor, and found that conditioned media from activated human $\mathrm{T}$ cells supported proliferation of this cell line. By constructing a complementary DNA expression library from activated human $\mathrm{T}$ cells, they successfully identified a four-helix-bundle cytokine most homologous to IL-15. This cytokine has been designated IL-21, with the receptor designated IL-21R. They further showed that IL-21 supports the proliferation of NK, B (co-stimulated with anti-CD40), and T (co-stimulated with anti-CD3) cells [10]. The amino acid sequence of IL-21R is most related to IL-2R $\beta$. IL-21R plus the common cytokine receptor $\gamma$ chain $(\gamma \mathrm{c})$ form the functional receptor for IL-21. IL-21R expression is lympho-hematopoietic restricted, but it is broadly found on B, T, NK, and dentritic cells (DCs). B cells, including resting B cells, express the highest level of IL-21R. Resting naive T cells express low-level of IL-21R, however, it is elevated upon TCR stimulation. In contrast to IL-21R expression, IL-21 production has been identified only in activated CD4 ${ }^{+}$ $\mathrm{T}$ helper cells and NKT cells. Thus, T helper cells and NKT cells may coordinate immune responses by providing IL-21 signals to multiple immune cell types [2].

\section{The Molecular Basis of IL-21 Production}

In the first paper describing IL-21, Parrish-Novak et al. [10] indicated that $\mathrm{CD} 4^{+} \mathrm{T}$ cells (but not $\mathrm{CD} 8^{+} \mathrm{T}$ cells, B cells, and monocytes) express IL21 transcripts upon activating stimulation. Later, anti-CD3 stimulation and Mycobacterium bovis bacillus Calmette Guerin stimulation were also shown to induce IL-21 production in NKT cells [12,13]. Herein, we focus on the regulation of IL-21expression in $\mathrm{CD}^{+} \mathrm{T}$ cells. Intriguingly, activated $\mathrm{CD} 4^{+} \mathrm{T}$ cells are the major producers for IL-2 and IL-21, and the genes encoding IL-2 and IL-21 are adjacent to each other. Similar to IL-2 gene expression, IL-21 gene expression also requires TCR stimulation via both calcium and protein kinase $\mathrm{C}$ signaling. Nonetheless, in pre- 
activated (TCR-stimulated) T cells, calcium signaling alone can induce expression of IL-21, but not IL-2 [14].

TCR signaling contributes to IL-2 gene transcription by inducing activator protein 1 (AP-1), increases the levels of active NF- $\kappa$ B p65/rel, and causes translocation of nuclear factor of activated T cells (NFAT) into the nucleus. These transcription factors, in conjunction with constitutive factors, bind to the minimal promoter of IL-2 for gene transcription [15]. The contribution of TCR signal in IL-21 gene transcription has also been investigated. NFAT binding sites in the IL-21 promoter region also contribute to IL-21 gene transcription [2,14]. AP-1 transcription factors are dimers of JUN, FOS, MAF and activating transcription factor (ATF) family proteins. An AP-1 protein, BATF, forms heterodimers with JUN. Under Th17 polarizing conditions (which generally induce expression of both IL-17 and IL-21), BATFdeficient T cells failed to produce IL-21 and IL-17, but produce normal levels of IL-2 and IFN- $\gamma$. Therefore, IL-21 and IL-2 production are differently controlled at transcription level, and BATF has a critical role in IL-21 but not IL-2 production [16].

Among co-stimulatory signals, inducible T cell costimulator (ICOS) has been most extensively investigated in its relation to IL-21 production. Bauquet et al. [17] recently showed that ICOS induces expression of the transcription factor c-Maf, which in turn controls IL-21 expression. Indeed, c-Maf-deficient T cells exhibit impaired ability to produce IL-21 [17]. A defect in IL-21 production further regulates the development of Th17 and ICOS-expressing $\mathrm{T}_{\mathrm{FH}}$ cells, which will be discussed in details in the following section. Vinuesa et al. [18] identified a RING-type ubiquitin ligase protein, roquin, as a repressor of ICOS. The roquin-mutated mouse strain, sanroque, exhibits excessive IL-21 production, elevated numbers of $\mathrm{T}_{\mathrm{FH}}$ cells and germinal centers (GCs), while developing high titres of autoantibodies and systemic pathology consistent with lupus [18].

In terms of the relation between environmental cytokines and IL-21-production by CD4 ${ }^{+} \mathrm{T}$ cells, both IL-6 and IL-21 itself were identified as the potent inducers for IL-21 expression. IL-6 activates Stat1 and Stat3. IL-21 signaling activates Stat1, Stat3, and Stat5. Of these, the activation of Stat 3 is the most sustained [19]. Cre-loxP-mediated deletion of Stat 3 in T cells abrogates of expression of IL-21 mRNA in response to IL-6 or IL-21, indicating the critical role of Stat3 in IL-21 gene transcription [20]. Importantly, effects of IL-6/IL-21 on the expression of IL-21 are completely abrogated in IFN regulatory factor 4 (IRF4)-deficient T cells, although IL-21-induced STAT3 activation is unimpaired [21]. Molecules regulating IRF4 phosphorylation (e.g. ROCK2) or transcriptional action (e.g. Def6) also affect IL-21 gene expression [22,23]. Therefore, Stat 3 and IRF4 are critical transcriptional regulators and play non-redundant roles for IL-21 production. In contrast to other members of IRF family, IRF4 expression in T cells is primarily regulated by activating stimulation and not by type I/ II interferons [24]. Genome-wide ChIP-Seq mapping of STAT3- and IRF4-binding sites showed that most regions with IL-21-induced STAT3 binding also bind IRF4. Moreover, ChIP-Seq analysis of IRF4-/- T cells showed greatly diminished STAT3 binding after IL-21 treatment. Therefore, IL-21 signaling causes broad cooperative gene regulation by STAT3 and IRF4 [25], which may also coordinately induce expression of IL-21 itself.

Taken together, IL-21 production by $\mathrm{CD}^{+} \mathrm{T}$ cells requires activating stimulation (transcriptional activities of BATF and IRF4, etc.), and is also enhanced by ICOS/c-Maf and IL-6/IL-21/Stat3 signals. Due to the significance of IL-21 in controlling immune responses, the regulation of its production should be further investigated. For instance, IL-27 signaling has recently been shown to enhance IL-21 production in $\mathrm{T}_{\mathrm{FH}}$ cells in a Stat3-dependent manner [26]. 


\section{The Interplay between IL-21 Signaling and T cell Differentiation}

Th17 cells have been shown to be potent inducers to tissue inflammation and autoimmune diseases. These helper cells produce various cytokines including IL-17a, IL-17f, IL-21, and IL-22. Th17 cell differentiation was initially found to be induced by TGF- $\beta 1$ in combination with IL-6, and to depend on the transcription factor retinoic acid-related orphan receptor $\gamma \mathrm{t}$ (ROR $\gamma \mathrm{t}$ ). Since IL-6 is present in the TGF- $\beta 1 / \mathrm{IL}-6$ polarizing condition, it is not surprising that IL-21 is produced by Th17 cells. Indeed, IL-21 gene expression is mainly induced by IL-6/Stat3, but not by TGF- $\beta 1$ signaling and ROR $\gamma t$ activity. By contrast, under TGF- $\beta 1 /$ IL- 6 polarizing condition, both TGF- $\beta 1$ and IL- 6 are required for optimal ROR $\gamma \mathrm{t}$ and IL-17 expression [20]. Intracellular staining of IL-21 and IL-17 in CD4 ${ }^{+}$T cells polarized by TGF$\beta 1 / \mathrm{IL}-6$ further showed that some cells express both IL-17 and IL-21, but the majority of IL-21-producing cells do not produce IL-17. TGF- $\beta 1$ even decreases IL-6-induced IL-21 production in activated $\mathrm{CD} 4^{+} \mathrm{T}$ cells [27]. Therefore, most IL-21-producing cells may develop preferentially in an IL-6-rich environment devoid of TGF- $\beta 1$, though Th17 cells induce by TGF- $\beta 1 / \mathrm{IL}-6$ also produce IL-21.

Since both IL-21 and IL-6 activate Stat3, TGF- $\beta 1$ combined with IL-21 exhibits similar effect to TGF- $\beta 1 /$ IL- 6 with respect to Th17 cell differentiation [28,29]. Furthermore, IL-21 not only serves as an autocrine regulation of its own production, but also induces IL-23R expression. In the absence of IL-21 signaling (using IL-21- or IL-21R-deficient T cells), TGF- $\beta 1 /$ IL- 6 signaling induces fewer Th17 cells and does not induce IL-23R expression [20,29]. IL-21 and IL-23 up-regulate and sustain ROR $\gamma t$ expression, maintaining Th17 cell phenotype [2]. Thus, IL-21 is critical for Th17 cell generation and maintenance.

$\mathrm{T}_{\mathrm{FH}}$ cells are the specialized helper cells for $\mathrm{B}$ cell function, and express the master transcriptional regulator Bc16. They also express the chemokine receptor CXCR5 for migration to B cell zones (follicles) of secondary lymphoid tissues. Other surface markers include ICOS, PD-1, and SAP (SH2D1A). The molecular basis of $\mathrm{T}_{\mathrm{FH}}$ cell differentiation is not fully defined. Nurieva et al. [30] have shown that $\mathrm{T}_{\mathrm{FH}}$ cell generation is dependent on ICOS signaling and IL-21/IL-6/Stat3 signaling. Vogelzang et al. [31] further indicated that IL-21 facilitates the generation of $\mathrm{T}_{\mathrm{FH}}$ cells, which in turn help B cells to produce highaffinity antibody in GCs. Moreover, $\mathrm{T}_{\mathrm{FH}}$ cells are characterized by production of IL-21, reflecting the fact that signaling molecules affecting IL-21 gene expression (e.g. IL-21/IL-6/ Stat3/IRF4; ICOS/c-Maf; and Batf) also control $\mathrm{T}_{\mathrm{FH}}$ cell differentiation [32]. On the contrary, IL-21/IL-6/Stat3 not only induces the expression of IL-21 and Bcl6, but also potently triggers the expression of Blimp1, which is an antagonist of Bcl6 and inhibits $\mathrm{T}_{\mathrm{FH}}$ differentiation [33]. The precursors of $\mathrm{T}_{\mathrm{FH}}$ cells must therefore apply additional molecular regulation to induce Bcl6, but inhibit Blimp1 expression.

IL-21 is not essential for Th1 and Th2 cell differentiation. While IL-21 may impair the production of IFN- $\gamma$ during Th1 cell differentiation, it has no effect on T-bet expression and overall Th1 program. In addition, Th1 and Th2 cells also produce IL-21, though at lower levels when compared to Th17 and $\mathrm{T}_{\mathrm{FH}}$ cells. McGuire et al. [34] identified CD4 ${ }^{+} \mathrm{CCR} 9^{+}$ cells in the pancreas of diabetic NOD mice. These $\mathrm{CCR} 9^{+}$cells express large amounts of IL-21 locally in the inflamed tissues to mediate autoimmunity. Possibly, as long as they receive the proper signals during priming (e.g. IL-21/IL-6/Stat3/IRF4; ICOS/c-Maf; and Batf), activated $\mathrm{CD} 4^{+}$cells can produce IL- 21 and control various immune responses.

\section{IL-21 Effects on B cell Function}

Two years after the identification of IL-21 and IL-21R, Ozaki et al. [35] had generated the IL-21 $\mathrm{R}^{-/}$mice. Different from the deficiencies of IL-2, IL-7 and IL-15 $\gamma \mathrm{c}$ cytokine signals, $\mathrm{IL}-21 \mathrm{R}^{-/-}$mice have normal lymphoid development and have absence of severe 
autoimmunity. Nevertheless, after immunization, these animals exhibit decreased levels of $\mathrm{IgG1}$, but higher levels of IgE, when compared to wild type mice. Knock out of IL-4 in $\mathrm{IL}-21 \mathrm{R}^{-/-}$mice potently abrogates both $\mathrm{IgG}$ and IgE production, suggesting that IL-4 is required for the enhanced IgE production seen in IL-21R ${ }^{-/}$mice. Therefore, IL-21 and IL-4 coordinately regulate immunoglobulin production, as IL-21 augments IgG production but inhibits IL-4-mediated IgE production [35]. IL-6 also promotes IgG response possibly due to its capability to increase IL-21 secretion from $\mathrm{CD}^{+}$helper cells [36]. The inhibitory effect of IL-21 on IgE production may attribute to its capability to selectively induce apoptosis of IgE-expressing B cells [36].

The molecular basis of the profound IL-21 effects on B cells remains obscure. GCs are specific sites within secondary lymphoid tissues where B cells proliferate, undergo somatic Ig hypermutation and differentiate into either plasma cells or long-lived memory B cells. Interaction between $\mathrm{B}$ cells and $\mathrm{IL}-21$-producing $\mathrm{T}_{\mathrm{FH}}$ cells is required for $\mathrm{GC}$ formation and for selection of somatically mutated GC B cells with improved affinity for antigen. Two recent papers have shown that IL-21 produced by $\mathrm{T}_{\mathrm{FH}}$ acts directly on GC B cells to control their proliferation, response to antigen, and differentiation [37,38]. IL-21/Stat3 signaling in B cells potently induces Blimp1 and Bcl6 [39], which are mutually exclusive transcriptional factors for the differentiation of plasma cells and memory B cells, respectively. Revealing the interplay between Stat3, Blimp1, Bcl6, and other signaling molecules in GC B cells would be critical for better understanding how to control IL-21-mediated humoral responses.

As mentioned earlier, $\mathrm{T}_{\mathrm{FH}}$ cells in roquin-mutated mice produce high levels of IL-21 and trigger the development of a B cell-mediated lupus-like pathology [18]. In the BXSB.B6$\mathrm{Yaa}^{+}$mouse model of systemic lupus erythematiosus (SLE) and the lupus-prone MRL-Fas/ Ipr mouse model, B cell-mediated renal autoimmune phenotypes are accompanied by high levels of IL-21 [40,41]. Interestingly, IL-21R deficiency completely prevents characteristic early mortality in BXSB. B6- $\mathrm{Yaa}^{+}$mice by diminishing renal disease [41]. More strikingly, in vivo neutralization of IL-21 by administration of IL-21R.Fc fusion protein reduces levels of circulating dsDNA autoantibodies and total sera IgG1 and IgG2a, which in turn prevents proteinuria, IgG glomerular deposits, and glomerular basement membrane thickening in MRL-Fas/lpr mice [40]. Blocking IL-21 signal may therefore represent a promising novel therapeutic approach to treat B cell-mediated autoimmunity.

\section{The Requirement of IL-21 for Sustained T cell Function}

Although not critical for the development and homeostasis of naïve T cells, IL-21 is one of major cytokines controlling $\mathrm{T}$ cell responses after they have encountered cognate antigens. In addition to polarizing $\mathrm{CD} 4^{+}$helper T cell differentiation through Stat3 signal, IL-21 was initially shown to promote enhanced expansion of $\mathrm{CD} 8^{+} \mathrm{T}$ cells co-stimulated with TCR signal [10]. Zeng et al. [42] further indicated that IL-21 synergistically acts with IL-15 to not only promote the proliferation, but also augment IFN- $\gamma$ production and cytolytic activity of $\mathrm{CD}^{+}$effector T cells. Nevertheless, other $\gamma \mathrm{c}$ cytokines, IL-2, IL-7 and IL-15, have already been shown to execute $\mathrm{T}$ cell response by controlling clonal-expansion and memory cell generation of anti-specific T cells. Is IL-21 a redundant cytokine to help $\mathrm{CD}^{+}{ }^{+}$effector T cells?

In 2009, three groups simultaneously reported that IL-21 is required for the specific CD8 ${ }^{+} \mathrm{T}$ cell response and control of pathogen during chronic, but not acute, viral infection [3-5]. IL-21 $1^{-/}$and IL-21 $\mathrm{R}^{-/-}$mice were infected with acute lymphocytic choriomeningitis virus (LCMV)-Armstrong and chronic LCMV-clone 13 infections. Upon LCMV-Armstrong infection, both wild type and knock out mice exhibited efficient viral control, normal CD8 ${ }^{+}$ effector $\mathrm{T}$ cell expansion, function, memory homeostasis, and even recall responses. 
However, while wild type mice were capable of slowly controlling LCMV-clone 13 infection, IL-21 $1^{-1-}$ and IL-21 $\mathrm{R}^{-1-}$ mice were stricken with persistent viral infection and dysfunction of virus-specific $\mathrm{CD} 8^{+} \mathrm{T}$ cells (indicated by lower antigen-specific $\mathrm{T}$ cell numbers and impaired cytokine production several weeks after infection) [3-5]. Because IL-21 is predominantly produced by activated $\mathrm{CD} 4^{+} \mathrm{T}$ cells, these studies suggest that $\mathrm{CD} 4^{+}$ $\mathrm{T}$ helper cells selectively use IL-21 to sustain the survival or effector function of antigenspecific $\mathrm{CD} 8^{+} \mathrm{T}$ cells during an exhausting combat against chronic infection.

$\mathrm{T}$ cells play a central role in mediating autoimmunity in diabetic NOD mice. Deficiency in IL-21 or IL-21R renders NOD mice resistant to insulitis, which in turn completely prevents the onset of type 1 diabetes [6,7]. Moreover, overexpression of IL-21 in pancreatic $\beta$ cells results in spontaneous type 1 diabetes in normally diabetes-resistant C57B1/6 mice [6]. On the contrary, IL-21 or IL-21R deficient mice immunized with myelin oligodendrocyte glycoprotein (MOG) peptide [which causes T cell-mediated autoimmune experimental encephalitis (EAE)] developed EAE with disease scores comparable to those of control mice $[43,44]$. NOD mice develop insulitis at about 4 weeks old and overt diabetes by $12-20$ weeks, whereas EAE onset is quickly induced within a week of MOG immunization. Therefore, in the context of T cell-mediated autoimmunity, it would be interesting to determine whether IL-21 regulates "chronic", but not "acute", T cell responses by sustaining effector T cell function. Hence, blocking IL-21 signal may be a potential therapeutic approach for some, but not all, autoimmune diseases.

The concept of $\mathrm{T}$ cell exhaustion is used to describe the state of $\mathrm{T}$ cell dysfunction, which is commonly observed in chronic infection and cancer studies. As antigen load increases and persists, T cells may progress through expression of inhibitory receptors (e.g. PD-1 and LAG-3), reduced production of effector cytokines, and eventually loss of function or death [8]. It is possible that IL-21may sustain effector $\mathrm{T}$ cell function during chronic viral infection by preventing them from being exhausted [3-5]. Interestingly, IL-21 also exerts potent anti-tumor effects in several models [2]. Continuous study of the relationship between IL-21 and T cell exhaustion as well as the dynamic interplay between IL-21 and other $\gamma \mathrm{c}$ cytokines will facilitates the use of IL-21 as a therapy.

\section{Unresolved Issues in Controlling Alloreactive T and B cells}

$\mathrm{T}$ cells are requisite mediators of allograft rejection. Alloreactive $\mathrm{T}$ cells are mainly primed in secondary lymphoid organs [45], where graft-derived donor passenger leukocytes present intact donor MHC:peptide to alloreactive T cells and trigger the direct recognition pathway $[46,47]$. Donor antigens can also be engulfed by the recipient's APCs and presented on self MHC molecules, which in turn execute the indirect recognition pathway to activate alloreactive $\mathrm{T}$ cells. These $\mathrm{T}$ cells subsequently migrate to and destroy allografts by a variety of effector pathways. These include direct destruction of graft cells via Fas or granzyme B/ perforin, activation of monocytes/macrophages to trigger delayed-type hypersensitivity (DTH) responses, upregulation of alloantibody production to subsequently activate complement/cogulation pathways, mediation of antibody-dependent cellular cytotoxicity [48], and secretion IL-4 and IL-5 to promote esonophil-mediated graft destruction [49].

In order to maintain allograft survival, organ-transplanted patients continuously take many immunosuppressive drugs (i.e. cyclosporine and tacrolimus combined with other drugs) to control $\mathrm{T}$ cell activation. For instance, cyclosporine and tacrolimus inhibit the action of calcineurin, and thus prevent the TCR-mediated nuclear translocation of NFAT, which is required for transcription of genes that promote $\mathrm{T}$ cell survival and expansion. Nevertheless, NFAT is also required for transcription of genes responsible for $\mathrm{T}$ cell tolerance (e.g. Egr2, Egr3, Cbl-b, itch, and GRAIL) [50]. Therefore, although constant use of calcineurin 
inhibitors prevents alloreactive $\mathrm{T}$ cell response, it may also interrupt the process of $\mathrm{T}$ cell tolerance. In addition, these drugs are associated with significant toxicity (e.g. nephrotoxicity) and increased risk for opportunistic infections and malignancy. A major outstanding challenge in the transplantation field is, therefore, to design therapeutic regimens that selectively eliminate or functionally impair alloreactive $\mathrm{T}$ cells while avoiding systemic immunosuppression.

$\mathrm{T}$ and B lymphocytes often work together to coordinate adaptive immune responses. T cell help is required for maximal antibody production against many antigens [51], while B cells can present antigens and produce cytokines to support $\mathrm{T}$ cell responses [52]. In the context of transplantation, acute allograft rejection begins days after transplantation and involves acute cellular rejection (ACR) and antibody-mediated rejection (AMR). Conventional antirejection therapies generally prevent ACR, however, AMR is resistant to these therapies and is associated with a poorer prognosis than pure ACR [53,54]. Therapies with intravenous immunoglobulin (IVIG), plasmapheresis (PP), anti-CD20 depleting Ab, and anti-CD19 depleting $\mathrm{Ab}$ have been used to treat AMR by non-selectively targeting B cells, plasma cells, or antibodies. The long-term survival and function of the grafts in recipients receiving these treatments as well as the potential side effects of these therapies are still areas requiring further study [48]. Because activation and antibody production of conventional B cells requires $\mathrm{T}$ cell help, we hypothesize that CMR may be prevented by interrupting such $\mathrm{T}$ cell help. Nevertheless, the role of $\mathrm{T}_{\mathrm{FH}}$ cells and IL-21 (critical for helping B cells) in transplant rejection remain largely unknown.

\section{Prospective Role of IL-21 in Transplantation Immunology}

Transient inhibition of TCR and co-stimulatory signals modulates T cell activation and induces long-term allograft survival in animal models. However, functional alloreactive cells may persist in recipients and prohibit the induction of transplantation tolerance [55]. Thus, efforts have also been input to blocking signals of $\gamma$ c cytokines (in particular IL-2, IL-15, and IL-21), which is required for clonal expansion, effector function, and survival of antigen-specific cells. Because $\gamma \mathrm{c}$ activates JAK3 to promote nuclear translocation of STAT transcription factors, many JAK3 inhibitors were developed and have been shown to prevent allograft rejection. Tofacitinib (CP-690550) is a JAK3 inhibitor developed by Pfizer, and requires only nanomolar concentrations to inhibit JAK3 expression in cultured cells. Tofacitinib has been shown to prevent allograft rejection in various murine transplantation models [56,57] as well as in life-support kidney transplantations in Cynomolgus monkeys [58,59]. Recently, a phase IIa trail conducted a pilot study comparing the effectiveness of tofacitinib with tacrolimus in kidney transplantation [60]. Tofacitinib treatment exhibited high immunosuppressive potency, but tofacitinib-treated patients also showed higher rates of BK virus nephropathy and cytomegalovirus-mediated disease than the tacrolimus-treated group [60]. In contrast to JAK3 inhibitors, an IL-2 receptor antagonist (daclizumab) has been safely used for over 10 years as a common induction therapy in clinic transplantation. The use of daclizumab even facilitates the design of therapeutic protocols with steroidsparing or calcineurin minimization [61]. Therefore, defining the actions of each $\gamma \mathrm{c}$ cytokine will facilitate the development of optimal tolerogenic therapies.

McGuire et al. [7] and Petrelli et al. [9] have recently investigated the effects of neutralizing IL-21 on islet graft survival. Normoglycemia was restored in diabetic NOD mice after IL-21R-Fc treatment and syngeneic islet transplantation [7]. Moreover, IL-21R-Fc combined with CTLA4-Ig also prolonged allogeneic islet graft survival in NOD mice [9]. These findings demonstrated that blockade of IL-21/IL-21R pathway may serve as a suitable treatment for type 1 diabetes or could even be a precondition for tolerogenic protocols in transplantation. Because of the complex biological functions of IL-21 in immune responses, 
several key aspects deserve to be further investigated: 1) It must be determined whether neutralizing IL-21 prolongs survival of other allografts, such as kidney and heart. 2) In the context of chronic viral infection with antigen persistence, both IL-2 and IL-21 direct the initial clonal expansion, whereas IL-21 subsequently prevents T cell exhaustion and sustains in long-term the function of effector T cells. Similarly, a transplanted organ also represents antigen persistence. Thus, the interplay between IL-21 and other $\gamma \mathrm{c}$ cytokines to sustain the function of antigen-experienced alloreactive $\mathrm{T}$ cells, particularly in the presence of other immunosuppressant, must be explored. 3) The molecular basis of IL-21 production and action in transplantation models must be determined. It is most critical to understand the fate of alloreactive T cells following extrinsic or intrinsic regulation of IL-6, IL-21, ICOS, Stat3, IRF4, Batf, Bc16, and Blimp1. 4) Finally, it is critical to ascertain whether neutralizing IL-21 modulates $\mathrm{T}_{\mathrm{FH}}$ cell function and inhibits AMR. Taken together, although IL-21 produced by activated $\mathrm{CD} 4^{+} \mathrm{T}$ cells has been shown in general to optimize and sustain the function of various immune subsets, the difference in nature between various immune responses (such as infection, autoimmunity, tumor immunity, and transplant rejection) affects "the stagespecific and context-specific signaling events involved in the response to IL-21" [2]. The unique aspects of IL-21 biology in transplantation setting should be investigated.

\section{Conclusion}

During the last twelve years, IL-21 and its receptor have been identified and subjected to detailed functional studies. IL-21 is predominantly produced by activated $\mathrm{CD} 4^{+} \mathrm{T}$ cells and NKT cells, and has profound effects on T cells, B cells, DCs, NK and NKT cells (Table 1). The molecular basis of both IL-21 production and action have been extensively investigated, advancing our understanding in of $\mathrm{B}$ cell differentiation and antibody production, $\mathrm{T}$ cell differentiation and exhaustion, as well as NKT cell-mediated innate immune response. Most importantly, IL-21 therapy exerts potent antitumor responses while blockade of the IL-21/ IL-21R pathway abrogates autoimmunity in several disease models. In transplantation, neutralizing IL-21 has also been shown to prolong islet graft survival, which is intriguing not only for its therapeutic potential but also for providing directions for investigating molecular mechanism of alloreactive $\mathrm{T}$ cell tolerance.

\section{Acknowledgments}

This work was supported by American Heart Association Grant 11SDG7690000, National Institutes of Health Grant P30 DK079638, Fondation de la Recherche en Transplantation Grant IIG201101, and National Natural Science Foundation of China (Grant No.81130056, 81070205, and 81100176).

\section{References}

1. Lechler RI, Sykes M, Thomson AW, Turka LA. Organ transplantation--how much of the promise has been realized? Nat Med. 2005; 11:605-613. [PubMed: 15937473]

2. Spolski R, Leonard WJ. Interleukin-21: basic biology and implications for cancer and autoimmunity. Annu Rev Immunol. 2008; 26:57-79. [PubMed: 17953510]

3. Elsaesser H, Sauer K, Brooks DG. IL-21 is required to control chronic viral infection. Science. 2009; 324:1569-1572. [PubMed: 19423777]

4. Yi JS, Du M, Zajac AJ. A vital role for interleukin-21 in the control of a chronic viral infection. Science. 2009; 324:1572-1576. [PubMed: 19443735]

5. Fröhlich A, Kisielow J, Schmitz I, Freigang S, Shamshiev AT, et al. IL-21R on T cells is critical for sustained functionality and control of chronic viral infection. Science. 2009; 324:1576-1580. [PubMed: 19478140]

6. Sutherland AP, Van Belle T, Wurster AL, Suto A, Michaud M, et al. Interleukin-21 is required for the development of type 1 diabetes in NOD mice. Diabetes. 2009; 58:1144-1155. [PubMed: 19208913] 
7. McGuire HM, Walters S, Vogelzang A, Lee CM, Webster KE, et al. Interleukin-21 is critically required in autoimmune and allogeneic responses to islet tissue in murine models. Diabetes. 2011; 60:867-875. [PubMed: 21357471]

8. Wherry EJ. T cell exhaustion. Nat Immunol. 2011; 12:492-499. [PubMed: 21739672]

9. Petrelli A, Carvello M, Vergani A, Lee KM, Tezza S, et al. IL-21 is an antitolerogenic cytokine of the late-phase alloimmune response. Diabetes. 2011; 60:3223-3234. [PubMed: 22013017]

10. Parrish-Novak J, Dillon SR, Nelson A, Hammond A, Sprecher C, et al. Interleukin 21 and its receptor are involved in NK cell expansion and regulation of lymphocyte function. Nature. 2000; 408:57-63. [PubMed: 11081504]

11. Ozaki K, Kikly K, Michalovich D, Young PR, Leonard WJ. Cloning of a type I cytokine receptor most related to the IL-2 receptor beta chain. Proc Natl Acad Sci U S A. 2000; 97:11439-11444. [PubMed: 11016959]

12. Harada M, Magara-Koyanagi K, Watarai H, Nagata Y, Ishii Y, et al. IL-21-induced Bepsilon cell apoptosis mediated by natural killer T cells suppresses IgE responses. J Exp Med. 2006; 203:2929-2937. [PubMed: 17178921]

13. Coquet JM, Kyparissoudis K, Pellicci DG, Besra G, Berzins SP, et al. IL-21 is produced by NKT cells and modulates NKT cell activation and cytokine production. J Immunol. 2007; 178:28272834. [PubMed: 17312126]

14. Kim HP, Korn LL, Gamero AM, Leonard WJ. Calcium-dependent activation of interleukin-21 gene expression in T cells. J Biol Chem. 2005; 280:25291-25297. [PubMed: 15879595]

15. Malek TR. The biology of interleukin-2. Annu Rev Immunol. 2008; 26:453-479. [PubMed: 18062768]

16. Schraml BU, Hildner K, Ise W, Lee WL, Smith WA, et al. The AP-1 transcription factor Batf controls T(H)17 differentiation. Nature. 2009; 460:405-409. [PubMed: 19578362]

17. Bauquet AT, Jin H, Paterson AM, Mitsdoerffer M, Ho IC, et al. The costimulatory molecule ICOS regulates the expression of c-Maf and IL-21 in the development of follicular T helper cells and TH-17 cells. Nat Immunol. 2009; 10:167-175. [PubMed: 19098919]

18. Vinuesa CG, Cook MC, Angelucci C, Athanasopoulos V, Rui L, et al. A RING-type ubiquitin ligase family member required to repress follicular helper $\mathrm{T}$ cells and autoimmunity. Nature. 2005; 435:452-458. [PubMed: 15917799]

19. Zeng R, Spolski R, Casas E, Zhu W, Levy DE, et al. The molecular basis of IL-21-mediated proliferation. Blood. 2007; 109:4135-4142. [PubMed: 17234735]

20. Zhou L, Ivanov II, Spolski R, Min R, Shenderov K, et al. IL-6 programs T(H)-17 cell differentiation by promoting sequential engagement of the IL-21 and IL-23 pathways. Nat Immunol. 2007; 8:967-974. [PubMed: 17581537]

21. Huber M, Brüstle A, Reinhard K, Guralnik A, Walter G, et al. IRF4 is essential for IL-21-mediated induction, amplification, and stabilization of the Th17 phenotype. Proc Natl Acad Sci U S A. 2008; 105:20846-20851. [PubMed: 19088203]

22. Biswas PS, Gupta S, Chang E, Song L, Stirzaker RA, et al. Phosphorylation of IRF4 by ROCK2 regulates IL-17 and IL-21 production and the development of autoimmunity in mice. J Clin Invest. 2010; 120:3280-3295. [PubMed: 20697158]

23. Chen Q, Yang W, Gupta S, Biswas P, Smith P, et al. IRF-4-binding protein inhibits interleukin-17 and interleukin-21 production by controlling the activity of IRF-4 transcription factor. Immunity. 2008; 29:899-911. [PubMed: 19062315]

24. Biswas PS, Bhagat G, Pernis AB. IRF4 and its regulators: evolving insights in to the pathogenesis of inflammatory arthritis? Immunol Rev. 2010; 233:79-96. [PubMed: 20192994]

25. Kwon H, Thierry-Mieg D, Thierry-Mieg J, Kim HP, Oh J, et al. Analysis of interleukin-21-induced Prdm1 gene regulation reveals functional cooperation of STAT3 and IRF4 transcription factors. Immunity. 2009; 31:941-952. [PubMed: 20064451]

26. Batten M, Ramamoorthi N, Kljavin NM, Ma CS, Cox JH, et al. IL-27 supports germinal center function by enhancing IL-21 production and the function of T follicular helper cells. J Exp Med. 2010; 207:2895-2906. [PubMed: 21098093] 
27. Suto A, Kashiwakuma D, Kagami S, Hirose K, Watanabe N, et al. Development and characterization of IL-21-producing CD4+ T cells. J Exp Med. 2008; 205:1369-1379. [PubMed: 18474630]

28. Korn T, Bettelli E, Gao W, Awasthi A, Jäger A, et al. IL-21 initiates an alternative pathway to induce proinflammatory T(H)17 cells. Nature. 2007; 448:484-487. [PubMed: 17581588]

29. Nurieva R, Yang XO, Martinez G, Zhang Y, Panopoulos AD, et al. Essential autocrine regulation by IL-21 in the generation of inflammatory T cells. Nature. 2007; 448:480-483. [PubMed: 17581589]

30. Nurieva RI, Chung Y, Hwang D, Yang XO, Kang HS, et al. Generation of T follicular helper cells is mediated by interleukin-21 but independent of T helper 1, 2, or 17 cell lineages. Immunity. 2008; 29:138-149. [PubMed: 18599325]

31. Vogelzang A, McGuire HM, Yu D, Sprent J, Mackay CR, et al. A fundamental role for interleukin-21 in the generation of T follicular helper cells. Immunity. 2008; 29:127-137. [PubMed: 18602282]

32. Crotty S. Follicular helper CD4 T cells (TFH). Annu Rev Immunol. 2011; 29:621-663. [PubMed: 21314428]

33. Johnston RJ, Poholek AC, DiToro D, Yusuf I, Eto D, et al. Bcl6 and Blimp-1 are reciprocal and antagonistic regulators of T follicular helper cell differentiation. Science. 2009; 325:1006-1010. [PubMed: 19608860]

34. McGuire HM, Vogelzang A, Ma CS, Hughes WE, Silveira PA, et al. A subset of interleukin-21+ chemokine receptor CCR9+ T helper cells target accessory organs of the digestive system in autoimmunity. Immunity. 2011; 34:602-615. [PubMed: 21511186]

35. Ozaki K, Spolski R, Feng CG, Qi CF, Cheng J, et al. A critical role for IL-21 in regulating immunoglobulin production. Science. 2002; 298:1630-1634. [PubMed: 12446913]

36. Dienz O, Eaton SM, Bond JP, Neveu W, Moquin D, et al. The induction of antibody production by IL-6 is indirectly mediated by IL-21 produced by CD4+ T cells. J Exp Med. 2009; 206:69-78. [PubMed: 19139170]

37. Zotos D, Coquet JM, Zhang Y, Light A, D'Costa K, et al. IL-21 regulates germinal center B cell differentiation and proliferation through a B cell-intrinsic mechanism. J Exp Med. 2010; 207:365378. [PubMed: 20142430]

38. Linterman MA, Beaton L, Yu D, Ramiscal RR, Srivastava M, et al. IL-21 acts directly on B cells to regulate Bcl-6 expression and germinal center responses. J Exp Med. 2010; 207:353-363. [PubMed: 20142429]

39. Ozaki K, Spolski R, Ettinger R, Kim HP, Wang G, et al. Regulation of B cell differentiation and plasma cell generation by IL-21, a novel inducer of Blimp-1 and Bcl-6. J Immunol. 2004; 173:5361-5371. [PubMed: 15494482]

40. Herber D, Brown TP, Liang S, Young DA, Collins M, et al. IL-21 has a pathogenic role in a lupusprone mouse model and its blockade with IL-21R.Fc reduces disease progression. J Immunol. 2007; 178:3822-3830. [PubMed: 17339481]

41. Bubier JA, Sproule TJ, Foreman O, Spolski R, Shaffer DJ, et al. A critical role for IL-21 receptor signaling in the pathogenesis of systemic lupus erythematosus in BXSB-Yaa mice. Proc Natl Acad Sci U S A. 2009; 106:1518-1523. [PubMed: 19164519]

42. Zeng R, Spolski R, Finkelstein SE, Oh S, Kovanen PE, et al. Synergy of IL-21 and IL-15 in regulating CD8+ T cell expansion and function. J Exp Med. 2005; 201:139-148. [PubMed: $15630141]$

43. Coquet JM, Chakravarti S, Smyth MJ, Godfrey DI. Cutting edge: IL-21 is not essential for Th17 differentiation or experimental autoimmune encephalomyelitis. J Immunol. 2008; 180:7097-7101. [PubMed: 18490706]

44. Sonderegger I, Kisielow J, Meier R, King C, Kopf M. IL-21 and IL-21R are not required for development of Th17 cells and autoimmunity in vivo. Eur J Immunol. 2008; 38:1833-1838. [PubMed: 18546146]

45. Lakkis FG, Arakelov A, Konieczny BT, Inoue Y. Immunologic 'ignorance' of vascularized organ transplants in the absence of secondary lymphoid tissue. Nat Med. 2000; 6:686-688. [PubMed: 10835686] 
46. Talmage DW, Dart G, Radovich J, Lafferty KJ. Activation of transplant immunity: effect of donor leukocytes on thyroid allograft rejection. Science. 1976; 191:385-388. [PubMed: 1082167]

47. Larsen CP, Morris PJ, Austyn JM. Migration of dendritic leukocytes from cardiac allografts into host spleens. A novel pathway for initiation of rejection. J Exp Med. 1990; 171:307-314. [PubMed: 2404081]

48. Clatworthy MR. Targeting B cells and antibody in transplantation. Am J Transplant. 2011; 11:1359-1367. [PubMed: 21668625]

49. Le Moine A, Goldman M, Abramowicz D. Multiple pathways to allograft rejection. Transplantation. 2002; 73:1373-1381. [PubMed: 12023610]

50. Nurieva RI, Liu X, Dong C. Molecular mechanisms of T-cell tolerance. Immunol Rev. 2011; 241:133-144. [PubMed: 21488895]

51. Parker DC. T cell-dependent B cell activation. Annu Rev Immunol. 1993; 11:331-360. [PubMed: 8476565]

52. Rodríguez-Pinto D. B cells as antigen presenting cells. Cell Immunol. 2005; 238:67-75. [PubMed: 16574086]

53. Mauiyyedi S, Colvin RB. Humoral rejection in kidney transplantation: new concepts in diagnosis and treatment. Curr Opin Nephrol Hypertens. 2002; 11:609-618. [PubMed: 12394606]

54. Takemoto SK, Zeevi A, Feng S, Colvin RB, Jordan S, et al. National conference to assess antibody-mediated rejection in solid organ transplantation. Am J Transplant. 2004; 4:1033-1041. [PubMed: 15196059]

55. Miyahara Y, Khattar M, Schroder PM, Mierzejewska B, Deng R, et al. Anti-TCR $\hat{I}^{2}$ mAb induces long-term allograft survival by reducing antigen-reactive $\mathrm{T}$ cells and sparing regulatory $\mathrm{T}$ cells. Am J Transplant. 2012; 12:1409-1418. [PubMed: 22420295]

56. Kudlacz E, Perry B, Sawyer P, Conklyn M, McCurdy S, et al. The novel JAK-3 inhibitor CP-690550 is a potent immunosuppressive agent in various murine models. Am J Transplant. 2004; 4:51-57. [PubMed: 14678034]

57. Changelian PS, Flanagan ME, Ball DJ, Kent CR, Magnuson KS, et al. Prevention of organ allograft rejection by a specific Janus kinase 3 inhibitor. Science. 2003; 302:875-878. [PubMed: 14593182]

58. Borie DC, Larson MJ, Flores MG, Campbell A, Rousvoal G, et al. Combined use of the JAK3 inhibitor CP-690,550 with mycophenolate mofetil to prevent kidney allograft rejection in nonhuman primates. Transplantation. 2005; 80:1756-1764. [PubMed: 16378072]

59. Borie DC, Changelian PS, Larson MJ, Si MS, Paniagua R, et al. Immunosuppression by the JAK3 inhibitor CP-690,550 delays rejection and significantly prolongs kidney allograft survival in nonhuman primates. Transplantation. 2005; 79:791-801. [PubMed: 15818321]

60. Busque S, Leventhal J, Brennan DC, Steinberg S, Klintmalm G, et al. Calcineurin-inhibitor-free immunosuppression based on the JAK inhibitor CP-690,550: a pilot study in de novo kidney allograft recipients. Am J Transplant. 2009; 9:1936-1945. [PubMed: 19660021]

61. Campara M, Tzvetanov IG, Oberholzer J. Interleukin-2 receptor blockade with humanized monoclonal antibody for solid organ transplantation. Expert Opin Biol Ther. 2010; 10:959-969. [PubMed: 20415630]

62. Attridge K, Wang CJ, Wardzinski L, Kenefeck R, Chamberlain JL, et al. IL-21 inhibits T cell IL-2 production and impairs Treg homeostasis. Blood. 2012; 119:4656-4664. [PubMed: 22442347]

63. Van Belle TL, Nierkens S, Arens R, von Herrath MG. Interleukin-21 receptor-mediated signals control autoreactive T cell infiltration in pancreatic islets. Immunity. 2012; 36:1060-1072. [PubMed: 22579473]

64. Fina D, Sarra M, Fantini MC, Rizzo A, Caruso R, et al. Regulation of gut inflammation and th17 cell response by interleukin-21. Gastroenterology. 2008; 134:1038-1048. [PubMed: 18395085]

65. Jang E, Cho SH, Park H, Paik DJ, Kim JM, et al. A positive feedback loop of IL-21 signaling provoked by homeostatic CD4+CD25- T cell expansion is essential for the development of arthritis in autoimmune K/BxN mice. J Immunol. 2009; 182:4649-4656. [PubMed: 19342640]

66. Søndergaard H, Skak K. IL-21: roles in immunopathology and cancer therapy. Tissue Antigens. 2009; 74:467-479. [PubMed: 19845910] 
67. De Nitto D, Sarra M, Pallone F, Monteleone G. Interleukin-21 triggers effector cell responses in the gut. World J Gastroenterol. 2010; 16:3638-3641. [PubMed: 20677335]

68. Li J, Pan HF, Cen H, Tian J, Ma Y, et al. Interleukin-21 as a potential therapeutic target for systemic lupus erythematosus. Mol Biol Rep. 2011; 38:4077-4081. [PubMed: 21107711]

69. Yuan FL, Hu W, Lu WG, Li X, Li JP, et al. Targeting interleukin-21 in rheumatoid arthritis. Mol Biol Rep. 2011; 38:1717-1721. [PubMed: 20848219]

70. Hashmi MH, Van Veldhuizen PJ. Interleukin-21: updated review of Phase I and II clinical trials in metastatic renal cell carcinoma, metastatic melanoma and relapsed/refractory indolent nonHodgkin's lymphoma. Expert Opin Biol Ther. 2010; 10:807-817. [PubMed: 20384523] 
Table 1

Immunoregulatory effects of IL-21 on various cell types and immune responses.

\begin{tabular}{|c|c|c|}
\hline Cell type & IL-21 actions & References \\
\hline Th17 cells cells & $\begin{array}{l}\text { IL-21 is an autocrine cytokine for Th17 differentiation and up-regulates IL-23R expression to maintain } \\
\text { Th17 cell phenotype }\end{array}$ & {$[20,28,29]$} \\
\hline $\mathrm{T}_{\mathrm{FH}}$ & Facilitates $\mathrm{T}_{\mathrm{FH}}$ differentiation; IL-21 is a major effector cytokine of $\mathrm{T}_{\mathrm{FH}}$ & [30-32] \\
\hline Th1, Th2 cells & Inhibits IFN- $\gamma$ but increases other Th1 molecules; IL- 21 can be produced by Th1 and Th2 cells & [2] \\
\hline Treg cells & Counteracts Treg suppression by acting on conventional $\mathrm{T}$ cells & [62] \\
\hline CD8 T cells & Up-regulates proliferation and effector function; Sustains effector function during antigen persistence & [2-5] \\
\hline B cells & $\begin{array}{l}\text { Promotes B cell proliferation, plasma cell differentiation, IgG production, GC formation; Inhibits IgE } \\
\text { production by inducing apoptosis of IgE-expressing B cells }\end{array}$ & [35-39] \\
\hline DCs & IL-21R is required for antigen transport by DCs & [63] \\
\hline NKT cells & $\begin{array}{l}\text { Enhances survival, proliferation, granzyme B expression, cytokine production; NKT cells also produce } \\
\text { IL-21 }\end{array}$ & {$[12,13]$} \\
\hline \multicolumn{3}{|l|}{ Murine model } \\
\hline Infection & Controls chronic viral infection by sustaining CD8 $\mathrm{T}$ cell function & {$[3-5]$} \\
\hline SLE & $\begin{array}{l}\text { Mice with SLE produce high levels of IL-21; IL-21R deficiency or IL-21R.Fc treatment inhibits B cell- } \\
\text { mediated lupus pathology }\end{array}$ & {$[18,40,41]$} \\
\hline T1D & $\begin{array}{l}\text { IL- } 21 \text { over-expression in pancreatic } \beta \text { cells induces T1D in C57B1/6 mice; IL-21 or IL-21R deficiency } \\
\text { prevents T1D onset in NOD mice; IL-21R.Fc treatment prolongs islet graft survival; CCR } 9^{+} \text {Th cells in the } \\
\text { pancreas produce IL-21; IL-21 signal controls DC-mediated antigen transport }\end{array}$ & {$[6,7,9,34,63]$} \\
\hline IBD & IL-21 deficient mice are protected against colitis & [64] \\
\hline RA & IL-21R deficient $\mathrm{K} / \mathrm{BxN}$ mice inhibited the development of arthritis & [65] \\
\hline EAE & IL-21 or IL-21R deficiency does not prevent MOG-induced EAE & {$[43,44]$} \\
\hline Tumor & IL-21 monotherapy inhibits tumor growth in various models & [66] \\
\hline \multicolumn{3}{|l|}{ Human disease } \\
\hline Autoimmunity & $\begin{array}{l}\text { Polymorphisms in IL-21 or IL-21R genes associate with SLE, T1D, IBD, and RA; Elevated expression of } \\
\text { IL-21 or IL-21R was found in patients with SLE, IBD, and RA }\end{array}$ & [66-69] \\
\hline Tumor & $\begin{array}{l}\text { Recombinant IL-21 is undergoing Phase I and II testing for treatment of metastatic renal cell carcinoma, } \\
\text { metastatic melanoma and relapsed/refractory indolent non-Hodgkin's lymphoma }\end{array}$ & [70] \\
\hline
\end{tabular}

DCs: Dendritic Cells; EAE: Experimental Autoimmune Encephalomyelitis; GC: Germinal Center; IBD: Inflammatory Bowel Disease; MOG: Myelin Oligodendrocyte Glycoprotein; NKT: Natural Killer T; NOD: Non-Obese Diabetic; RA: Rheumatoid Arthritis; SLE: Systemic Lupus Erythematosus; T1D: Type 1 Diabetes; TFH: Follicular Helper T; Th: T Helper; Treg: Regulatory T 